\title{
Applications of FACTS devices for improving power system transient stability
}

- Dang Tuan Khanh

- Nguyen Van Liem

Ho Chi Minh city University of Technology, VNU-HCM, Vietnam

(Manuscript Received on July 15, 2015, Manuscript Revised August 30, 2015)

\section{ABSTRACT}

As the power demand has been increasing rapidly, today's modern power system becomes to be more complex and faces many challenges. It is envisaged that transient stability will play the important role in ensuring the steady state operation of power systems in the event of three phases fault or switching of lines. This paper investigates models of Flexible AC Transmission Systems (FACTS) and applications of FACTS devices for improving the rotor angle stability. FACTS devices are applicable in shunt connection Static Var Compensator (SVC), in series connection Thyristor-Controlled Series Capacitor (TCSC), or in the combination of both. Mathematical models of power systems having FACTS devices are set of Differential - Algebraic Equations (DAEs). Trapezoidal rule and Newton - Raphson method are applied to solve DAEs. The simulation results of rotor angles demonstrate the effectiveness and robustness of proposed the SVC and TCSC on transient stability enhancement of power systems.

Keywords: Angle stability, FACTS, power system, power system stability, transient stability, SVC, STATCOM, TCSC, UPFC

\section{INTRODUCTION}

Stability is always the important issue in today's modern power system. Power system stability may be broadly defined as that property of power system that enables it to remain in a state of operating equilibrium under normal operating conditions and to regain an acceptable state of equilibrium after being subjected to a disturbance [1]. This paper concentrates the rotor angle on analyzing transient stability. Rotor angle stability is the ability of interconnected synchronous machines of power systems to remain in synchronism. As FACTS devices are capable of

controlling the power flow in very fast manner, they can improve transient stability.

The paper is recognized as follows: Models of power system components and FACTS devices' models are represented in section 2. Section 3 discusses about models of power systems having SVC and TCSC. The mathematical model of power system having SVC and/or TCSC is presented in section 4. The simulation results in section 5 prove that FACTS devices used in power system are possibility of improving transient stability. 


\section{MODELS OF POWER SYSTEMS COMPONENTS AND FACTS DEVICES}

\subsection{Synchronous generator model}

In this paper, the synchronous generator is represented by fifth-order model in the $\mathrm{d}-\mathrm{q}$ axes having the rotor frame of reference [2].

$$
\left\{\begin{array}{l}
\dot{\boldsymbol{\Psi}}_{\mathrm{r}}=\mathbf{A}_{\mathrm{m}} \boldsymbol{\Psi}_{\mathrm{r}}+\mathbf{F}_{\mathrm{m}} \mathbf{I}_{\mathrm{S}}+\mathbf{V}_{\mathrm{r}} \\
\dot{\omega}_{\mathrm{r}}=\frac{\left(\mathrm{P}_{\mathrm{m}}-\mathrm{P}_{\mathrm{e}}\right)}{\mathrm{M}} \\
\dot{\delta}_{\mathrm{r}}=\omega_{\mathrm{r}}-\omega_{\mathrm{R}}
\end{array}\right.
$$

Where $\psi_{\mathrm{r}}, \omega_{\mathrm{r}}$ and $\delta_{\mathrm{r}}$ are rotor flux linkage vector, rotor angular frequency and rotor angle respectively; $\mathbf{V}_{\mathrm{r}}$ is the rotor voltage vector; $\mathrm{P}_{\mathrm{m}}$ and $\mathrm{P}_{\mathrm{e}}$ are the mechanical and electrical power respectively; $\mathbf{M}$ is the machine inertia constant; $\omega_{R}$ is the synchronous speed; $\mathbf{I}_{S}$ is the stator current vector and $\mathrm{E}_{\mathrm{fd}}$ is the field voltage; $\mathbf{A}_{\mathrm{m}}$ and $\mathbf{F}_{\mathrm{m}}$ are the matrices depending on machine parameters.

As excitation systems of synchronous generators play an vital role in their operation and can affect the systems dynamic response, it is necessary to model the excitation systems accurately in transient stability analysis. The inputs comprise the terminal voltage magnitude, its reference value and supplementary signal from power system stabilizer (PSS). The output of excitation is the field voltage. The excitation system dynamics can be represented by the set of first-order differential equation as follows [3, 4].

$\dot{\mathbf{x}}_{\mathrm{e}}=\mathbf{A}_{\mathrm{e}} \mathbf{x}_{\mathrm{e}}+\mathbf{C}_{\mathrm{e}}\left|\mathrm{V}_{\mathrm{s}}\right|+\mathbf{B}_{\mathrm{e}} \mathrm{V}_{\mathrm{PSS}}+\mathbf{D}_{\mathrm{e}} \mathrm{V}_{\mathrm{s}}^{\text {ref }}$

Where $\mathbf{x}_{e}$ is the state vector for the excitation system; $\mathrm{V}_{\mathrm{s}}, \mathrm{V}_{\mathrm{PSS}}, \mathrm{V}_{\mathrm{s}}^{\text {ref }}$ are the synchronous machine terminal voltage, supplementary signal from the PSS and voltage reference respectively. $\mathbf{A}_{\mathrm{e}}, \mathbf{B}_{\mathrm{e}}, \mathbf{C}_{\mathrm{e}}$ and $\mathbf{D}_{\mathrm{e}}$ are matrices of constant values which depends on the gains and time constants of the controller.

Governor is responsible for sensing the speed deviations in rotor, and then adjusting the mechanical power from the prime-mover to reduce speed deviations. Accurate modelling of the prime mover and governor which control the input mechanical power to the synchronous generator and the rotor speed is very important, especially in the stability studies. The inputs comprise the machine speed, its reference value and the initial power. The output is the machine power. The first-order differential equation set for describing the dynamics of the prime-mover and governor controller can be arranged in the following form [3, 4].

$$
\dot{\mathbf{x}}_{\mathrm{g}}=\mathbf{A}_{\mathrm{g}} \mathbf{x}_{\mathrm{g}}+\mathbf{C}_{\mathrm{g}} \omega_{\mathrm{r}}+\mathbf{B}_{\mathrm{g}} \omega^{\mathrm{ref}}+\mathbf{D}_{\mathrm{g}} \mathrm{P}_{\mathrm{m}}^{0}
$$

Where $\mathbf{x}_{\mathrm{g}}$ is the state vector the prime-mover and governor controller; $\omega^{\text {ref }}, \mathrm{P}_{\mathrm{m}}^{0}$ are the speed reference and the initial power respectively; $\mathbf{A}_{g}$, $\mathbf{B}_{g}, \mathbf{C}_{\mathrm{g}}$, and $\mathbf{D}_{g}$ are matrices of constant values which depend on the gains and time constants of the controller.

\subsection{Power System Stabiliser (PSS)}

The PSS has been the most common stabilizer to damp out oscillations. The machine speed, terminal frequency and power can be used as the input signals to the PSS. Figure 1 shows the general structure of a PSS [5].

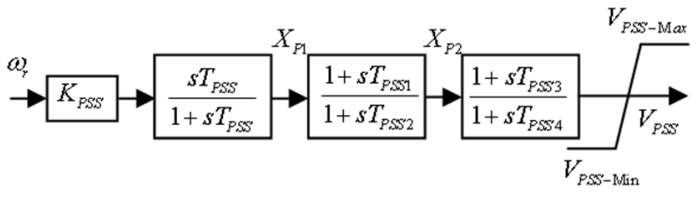

Figure 1. PSS control block diagram

Here, the rotor speed is used for the PSS input. The PSS output is added to the exciter voltage error signal and served as a supplementary signal. The differential equation set for representing the PSS controller can be arranged in the following form.

$$
\dot{\mathbf{x}}_{\mathrm{p}}=\mathbf{A}_{\mathrm{p}} \mathbf{x}_{\mathrm{p}}+\mathbf{C}_{\mathrm{p}} \dot{\omega}_{\mathrm{r}}
$$

Where $\mathbf{x}_{\mathrm{p}}$ is the vector of state variables of the PSS; $\mathbf{A}_{\mathrm{p}}$ and $\mathbf{C}_{\mathrm{p}}$ are matrices the elements of 
which depend on the gains and time constants of the PSS controller.

\subsection{Supplementary Damping Controller (SDC) model}

Block diagram of the SDC is shown in figure $2[6,7,8,9,10]$. The SDC block provides a modulation for power oscillation damping or small-disturbance stability improvement control. The SDC block contains a gain, a washout, leadlag blocks and limiter. Many different power system quantities have been proposed or used for the input signal to the SDC. They include voltage phase angle, frequency, line current and active power flow. The principal SDC function is to improve the inter-area mode damping. As there is a strong interaction between active power and electromechanical oscillations, the use of active power flow input appears to be most common one, which is also used in this paper.

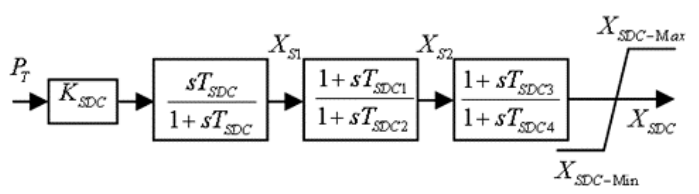

Figure 2. Control block diagram of SDC

The state equation for SDC can be described in compact form as follows:

$$
\dot{\mathbf{x}}_{\mathrm{su}}=\mathbf{A}_{\mathrm{su}} \mathbf{x}_{\mathrm{su}}+\mathbf{C}_{\mathrm{su}} \dot{\mathrm{P}}_{\mathrm{T}}
$$

Where $\mathbf{x}_{\mathrm{su}}=\left[\begin{array}{lll}\mathrm{X}_{\mathrm{S} 1} & \mathrm{X}_{\mathrm{S} 2} & \mathrm{X}_{\mathrm{SDC}}\end{array}\right]^{\mathrm{T}}$ is the vector of state variables of SDC; $\mathbf{A}_{\mathrm{su}}$ and $\mathbf{C}_{\mathrm{su}}$ are matrices the elements of which depend on gains and time constants of the SDC controller.

\subsection{Static Var Compensator (SVC) model}

SVC has been in use since the early 1960s. In addition to the main function of voltage or reactive power control, SVC can provide auxiliary control of active power flow through a transmission line. The possibility of controlling the transmittable power implies the potential application of this device for improving stability in power system. Block diagram form the control system of SVC used in this paper is shown in figure $3[6,11]$.

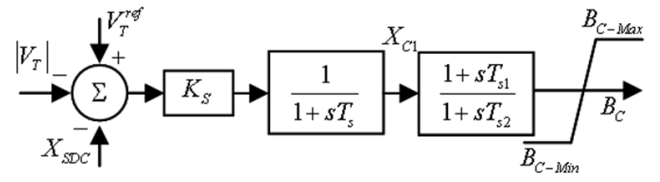

Figure 3. Control block diagram of SVC

The inputs comprise the terminal voltage $\left|V_{T}\right|$, its reference value $\mathrm{V}_{\mathrm{T}}^{\text {ref }}$ and supplementary signal $\mathrm{X}_{\mathrm{SDC}}$. The output is the SVC susceptance $B_{c}$. The state equations for SVC can be arranged as follows:

$$
\dot{\mathbf{x}}_{\mathrm{s}}=\mathbf{A}_{\mathrm{s}} \mathbf{X}_{\mathrm{s}}+\mathbf{C}_{\mathrm{s}}\left|\mathrm{V}_{\mathrm{T}}\right|+\mathbf{B}_{\mathrm{s}} \mathrm{X}_{\mathrm{SDC}}+\mathbf{D}_{\mathrm{s}} \mathrm{V}_{\mathrm{T}}^{\text {ref }}
$$

Where $\mathbf{x}_{\mathrm{s}}$ is the state vector for the SVC; $\mathbf{A}_{\mathrm{s}}, \mathbf{B}_{\mathrm{s}}, \mathbf{C}_{\mathrm{s}}$ and $\mathbf{D}_{\mathrm{s}}$ are matrices the elements of which depend on the gains and time constants of the controller.

\subsection{Thyristor-Controlled Series Capacitor (TCSC) model}

The series counterpart of the shunt-connected SVC is a TCSC, which is connected in series with transmission line. TCSC was introduced in 1986. TCSC is a FACTS device that can provide fast and continuous changes of transmission line impedance, and can regulate power flow in the line. The possibility of controlling the transmittable power also implies the potential application of this device for the improvement of power system stability [12, 13, 14].

Figure 4 is shown in block diagram form the control system of TCSC [7, 8, 9, 13].

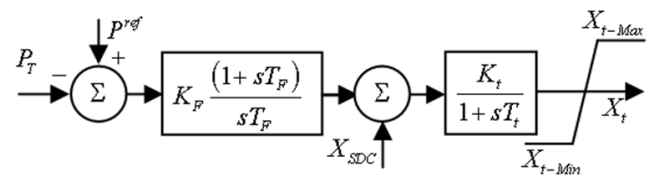

Figure 4. Control block diagram of TCSC

The inputs are composed of active power of transmission line $\mathrm{P}_{\mathrm{T}}$ and its reference value $\mathrm{P}^{\text {ref }}$ . The output is the reactance of TCSC $X_{t}$. The 
state equations for SVC can be arranged as follows:

$$
\dot{\mathbf{x}}_{\mathrm{t}}=\mathbf{A}_{\mathrm{t}} \mathbf{x}_{\mathrm{t}}+\mathbf{B}_{\mathrm{t}} \mathrm{X}_{\mathrm{SDC}}+\mathbf{C}_{\mathrm{t}} \mathrm{P}_{\mathrm{T}}+\mathbf{D}_{\mathrm{t}} \dot{\mathrm{P}}_{\mathrm{T}}+\mathbf{E}_{\mathrm{t}} \mathrm{P}^{\text {ref }}
$$

Where $\mathbf{x}_{t}$ is the state vector for the TCSC; $\mathbf{A}_{\mathrm{t}}, \mathbf{B}_{\mathrm{t}}, \mathbf{C}_{\mathrm{t}}, \mathbf{D}_{\mathrm{t}}, \mathbf{E}_{\mathrm{t}}$ are matrices the elements of which depend on the gains and time constants of TCSC.

Section 2 has the focus on models for individual components in power system such as synchronous generator, PSS, SDC, SVC, and TCSC.

\section{POWER SYSTEM HAVING FACTS DEVICES}

Section 3 presents models of power systems having each of FACTS devices.

\subsection{Power system model}

NB-node power system is considered in this paper. It is to be assumed that NG generators are connected to the power system. The network nodal current vector and voltage vector are related as follows:

$$
\mathbf{I}=\mathbf{Y} \mathbf{V}
$$

In general, all of the quantities in (8) are complex numbers. Separating (8) into real and imaginary parts and rearrange:

$$
\begin{gathered}
\mathbf{I}_{\mathrm{N}}=\mathbf{Y}_{\mathrm{N}} \mathbf{V}_{\mathrm{N}} \\
{\left[\begin{array}{c}
\mathbf{I}_{\mathrm{SN}} \\
\cdots \\
\mathbf{I}_{\mathrm{LN}}=0
\end{array}\right]=\left[\begin{array}{ccc}
\mathbf{Y}_{\mathrm{SS}} & \vdots & \mathbf{Y}_{\mathrm{SL}} \\
\cdots & \cdots & \cdots \\
\mathbf{Y}_{\mathrm{LS}} & \vdots & \mathbf{Y}_{\mathrm{LL}}
\end{array}\right]\left[\begin{array}{c}
\mathbf{V}_{\mathrm{SN}} \\
\cdots \\
\mathbf{V}_{\mathrm{LN}}
\end{array}\right]}
\end{gathered}
$$

Where $\mathrm{S}$ is set of generator nodes; $\mathrm{L}$ is set of non-generator nodes.

Based on (10), the following equations are obtained:

$$
\begin{gathered}
\mathbf{I}_{\mathrm{SN}}=\mathbf{Y}_{\mathrm{SS}} \mathbf{V}_{\mathrm{SN}}+\mathbf{Y}_{\mathrm{SL}} \mathbf{V}_{\mathrm{LN}} \\
0=\mathbf{Y}_{\mathrm{LS}} \mathbf{V}_{\mathrm{SN}}+\mathbf{Y}_{\mathrm{LL}} \mathbf{V}_{\mathrm{LN}}
\end{gathered}
$$

$\mathbf{I}_{\mathrm{SN}}$ and $\mathbf{V}_{\mathrm{SN}}$ in (11) and (12) are in the network D-Q frame of reference. The variables $\mathbf{I}_{\mathrm{SN}}$ and $\mathbf{V}_{\mathrm{SN}}$ are transformed into their corresponding d-q components $\mathbf{I}_{\mathrm{sM}}$ and $\mathbf{V}_{\mathrm{sM}}$ [15].

$$
\begin{gathered}
\mathbf{Y}_{\mathrm{SS}} \mathbf{T}_{\delta \mathrm{M}} \mathbf{V}_{\mathrm{sM}}-\mathbf{T}_{\delta \mathrm{M}} \mathbf{I}_{\mathrm{SM}}+\mathbf{Y}_{\mathrm{SL}} \mathbf{V}_{\mathrm{LN}}=0 \\
\mathbf{Y}_{\mathrm{LS}} \mathbf{T}_{\delta \mathrm{M}} \mathbf{V}_{\mathrm{sM}}+\mathbf{Y}_{\mathrm{LL}} \mathbf{V}_{\mathrm{LN}}=0
\end{gathered}
$$

Where $\mathbf{T}_{\delta \mathrm{M}}=\operatorname{diag}\left(\mathbf{T}_{\delta 1}, \mathbf{T}_{\delta 2}, \ldots, \mathbf{T}_{\delta, \mathrm{NG}}\right) ; \mathbf{T}_{\delta \mathrm{i}}$ is the transform matrix [15].

Complete power system model need following algebraic equation. Equation (15) is relationship between the stato current vector and the stator voltage vector.

$$
\mathbf{V}_{\mathrm{sM}}-\mathbf{P}_{\mathrm{M}} \boldsymbol{\Psi}_{\mathrm{rM}}+\mathbf{Z}_{\mathrm{M}} \mathbf{I}_{\mathrm{sM}}=0
$$

Algebraic Equations (13), (14) and (15) are represented power system's model. $\mathbf{V}_{\mathrm{sM}}, \mathbf{I}_{\mathrm{sM}}$ and $\mathbf{V}_{\text {LN }}$ are algebraic variables of network model.

\subsection{Power system with SVCs model}

Power system with NS SVCs is considered in this section. In D-Q frame, the network model for power system with SVCs can be described by:

$$
\left[\begin{array}{c}
\mathbf{I}_{\mathrm{SN}} \\
\cdots \\
\mathbf{I}_{\mathrm{LN}}=0
\end{array}\right]=\left[\begin{array}{ccc}
\mathbf{Y}_{\mathrm{SS}} & \vdots & \mathbf{Y}_{\mathrm{SL}} \\
\cdots & \cdots & \cdots \\
\mathbf{Y}_{\mathrm{LS}} & \vdots & \mathbf{Y}_{\mathrm{LL}}+\mathbf{Y}_{\mathrm{FS}}
\end{array}\right]\left[\begin{array}{c}
\mathbf{V}_{\mathrm{SN}} \\
\cdots \\
\mathbf{V}_{\mathrm{LN}}
\end{array}\right]
$$

$\mathbf{Y}_{\mathrm{FS}}$ is also separated into real and imaginary parts. $\mathbf{Y}_{\mathrm{FS}}$ and $\mathbf{Y}_{\mathrm{LL}}$ are the same dimension [15].

Based on (16), the following equations is obtained:

$$
\mathbf{Y}_{\mathrm{LS}} \mathbf{V}_{\mathrm{SN}}+\left(\mathbf{Y}_{\mathrm{L}}+\mathbf{Y}_{\mathrm{FS}}\right) \mathbf{V}_{\mathrm{LN}}=0
$$

Transforming $\quad \mathbf{V}_{\mathrm{SN}}$ in (17) into its corresponding d-q components $\mathbf{V}_{\mathrm{sM}}$ leads to:

$$
\mathbf{Y}_{\mathrm{LS}} \mathbf{T}_{\delta \mathrm{M}} \mathbf{V}_{\mathrm{sM}}+\left(\mathbf{Y}_{\mathrm{LL}}+\mathbf{Y}_{\mathrm{FS}}\right) \mathbf{V}_{\mathrm{LN}}=0
$$

Algebraic Equations (13), (15) and (18) are described power system with SVCs. These equations contain non-state variables.

\subsection{Power system with TCSCs model}

Power system with NT TCSCs is discussed in this section. In D-Q frame, the network model for power system with TCSCs can be described by: 


$$
\left[\begin{array}{c}
\mathbf{I}_{\mathrm{SN}} \\
\cdots \\
\mathbf{I}_{\mathrm{LN}}=0
\end{array}\right]=\left[\begin{array}{ccc}
\mathbf{Y}_{\mathrm{SS}} & \vdots & \mathbf{Y}_{\mathrm{SL}} \\
\cdots & \cdots & \cdots \\
\mathbf{Y}_{\mathrm{LS}} & \vdots & \mathbf{Y}_{\mathrm{LL}}+\mathbf{Y}_{\mathrm{FT}}
\end{array}\right]\left[\begin{array}{c}
\mathbf{V}_{\mathrm{SN}} \\
\cdots \\
\mathbf{V}_{\mathrm{LN}}
\end{array}\right]
$$

As each TCSC is connected in series with the transmission line, the TCSC reactance augment both the diagonal and off-diagonal of the network nodal admittance matrix for nodes which are connected to TCSC. $\mathbf{Y}_{\mathrm{FT}}$ is also separated into real and imaginary parts [15].

Based on (19), the following equation is obtained:

$$
\mathbf{Y}_{\mathrm{LS}} \mathbf{V}_{\mathrm{SN}}+\left(\mathbf{Y}_{\mathrm{L}}+\mathbf{Y}_{\mathrm{FT}}\right) \mathbf{V}_{\mathrm{LN}}=0
$$

Transforming $\quad \mathbf{V}_{\mathrm{SN}}$ in (20) into its corresponding d-q components $\mathbf{V}_{\mathrm{sM}}$ becomes:

$$
\mathbf{Y}_{\mathrm{LS}} \mathbf{T}_{\mathrm{\delta M}} \mathbf{V}_{\mathrm{SM}}+\left(\mathbf{Y}_{\mathrm{LL}}+\mathbf{Y}_{\mathrm{FT}}\right) \mathbf{V}_{\mathrm{LN}}=0
$$

Algebraic Equations (13), (15) and (21) are described power system having TCSCs. These equations contain non-state variables.

\section{THE SET OF DIFFERENTIAL - ALGEBRAIC EQUATIONS (DAES)}

The main outcome of this section is the composite set of DAEs of the power system having FACTS devices.

Differential equations of the model of power system having FACTS devices comprise (1), (2), (3), (4), (5), (6), and (7) in section 2. Depending on the types of FACTS devices connected the power system, the set of state equations is augmented with those for individual FACTS devices. These equations can be written in compact equation (22). Equations (13), (14), (15), (18), and (21) in section 3 are algebraic equations of the power system having FACTS devices. These equations can be also written in compact equation (23).

$$
\begin{aligned}
& \dot{\mathbf{x}}=\mathbf{f}(\mathbf{x}, \mathbf{w}) \\
& \mathbf{g}(\mathbf{x}, \mathbf{w})=0
\end{aligned}
$$

Where $\mathbf{x}$ is the vector of state variables; $\mathbf{w}$ is the vector of non-state variables; $\mathbf{f}, \mathbf{g}$ are nonlinear vector functions.

In order to validate the performance of power system under transient conditions, it is always desirable to carry out the time-domain simulations for the power system to investigate stability analysis. The time-domain solutions are implemented by solving simultaneously the set of DAEs (22) and (23). The set of differential equation in (22) is solved by using the Trapezoidal of integration as follows:

$$
\begin{aligned}
& \mathbf{x}_{(\mathrm{n}+1)}=\mathbf{x}_{(\mathrm{n})}+ \\
& \frac{\Delta \mathrm{t}}{2}\left(\mathbf{f}\left(\mathbf{x}_{(\mathrm{n}+1)}, \mathbf{w}_{(\mathrm{n}+1)}\right)+\mathbf{f}\left(\mathbf{x}_{(\mathrm{n})}, \mathbf{w}_{(\mathrm{n})}\right)\right)
\end{aligned}
$$

Where $\Delta \mathrm{t}$ is the time step length and $\mathrm{n}$ is the time step counter.

Equation (24) is rearranged to give:

$$
\begin{aligned}
& \left(\mathbf{x}_{(\mathrm{n}+1)}-\mathbf{x}_{(\mathrm{n})}\right)- \\
& \frac{\Delta \mathrm{t}}{2}\left(\mathbf{f}\left(\mathbf{x}_{(\mathrm{n}+1)}, \mathbf{w}_{(\mathrm{n}+1)}\right)+\mathbf{f}\left(\mathbf{x}_{(\mathrm{n})}, \mathbf{w}_{(\mathrm{n})}\right)\right)=0
\end{aligned}
$$

Combining equations (23) and (25), we have:

$$
\left\{\begin{array}{l}
\left(\mathbf{x}_{(\mathrm{n}+1)}-\mathbf{x}_{(\mathrm{n})}\right)- \\
\frac{\Delta \mathrm{t}}{2}\left(\mathbf{f}\left(\mathbf{x}_{(\mathrm{n}+1)}, \mathbf{w}_{(\mathrm{n}+1)}\right)+\mathbf{f}\left(\mathbf{x}_{(\mathrm{n})}, \mathbf{w}_{(\mathrm{n})}\right)\right)=0 \\
\mathbf{g}(\mathbf{x}, \mathbf{w})=0
\end{array}\right.
$$

Using Newton-Raphson method, the solutions for $\mathbf{x}$ and $\mathbf{w}$ are found by simultaneously solving DAEs (26). In this paper, rotor angle results are necessary to study stability analysis. Next section will present results of simulation in some cases.

\section{SIMULATION}

The computer programming is necessary to simulate power systems having FACTS devices. This programming is helpful to students, engineers who do research in power system stability because of the expensive commercial software. 


\subsection{Case 1}

Case 1 considers the two-generator power system with or without FACTS devices as figure 5. The shunt FACTS device SVC is equipped at bus 4 while TCSC is connected between bus 3 and bus 4 .

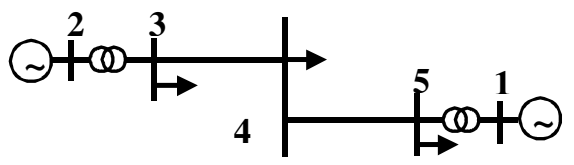

Figure 5. Power system in case 1

The disturbance is a three phases fault at bus 3. The fault is initiated at time $t=0.5 \mathrm{~s}$ and the fault clearing time is $0.2 \mathrm{~s}$. Figure 6 and figure 7 show the transient of power sytem.

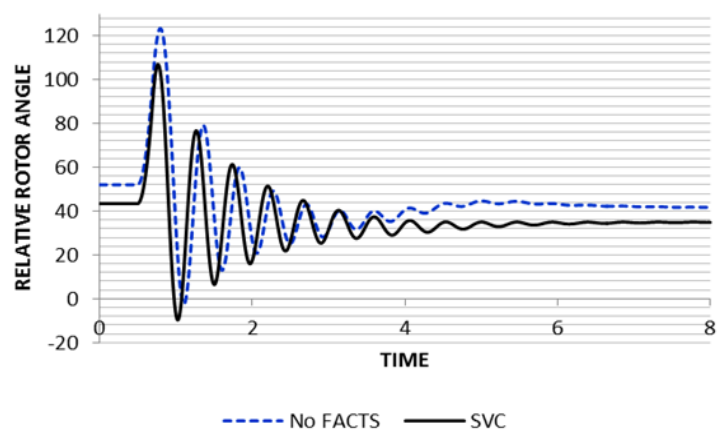

Figure 6. Relative rotor angle response to transient distubance in case 1 with SVC at bus 4
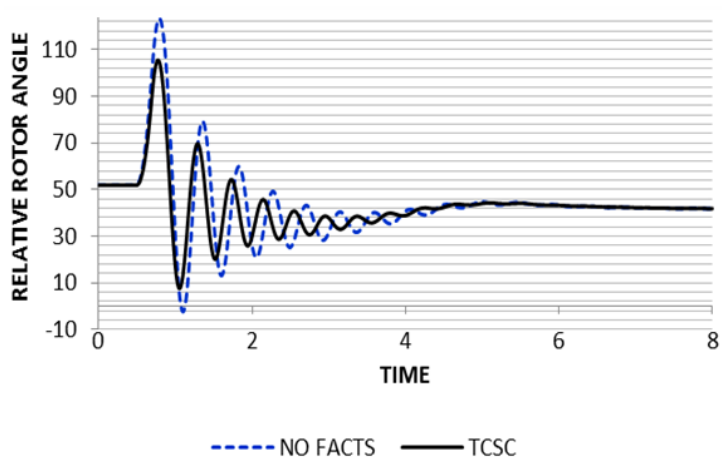

Figure 7. Relative rotor angle response to transient distubance in case 1 with TCSC between bus 3 and bus 4

It can be observed that if properly used FACTS devices, both SVC and TCSC can improve power system stability.

\subsection{Case 2}

Disturbances such as three phases fault or a switching of line are discussed in case 2 as figure 8. The series FACTS device TCSC is equiped between bus 5 and bus 2 and the shunt FACTS device SVC is equieped at bus 4 .

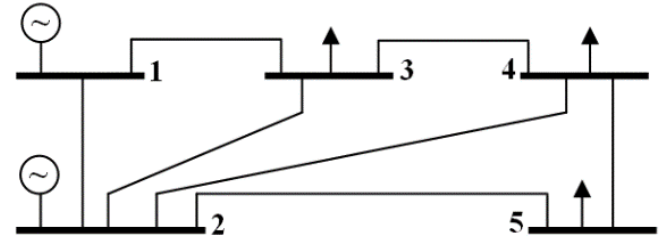

Figure 8. Power system in case 2

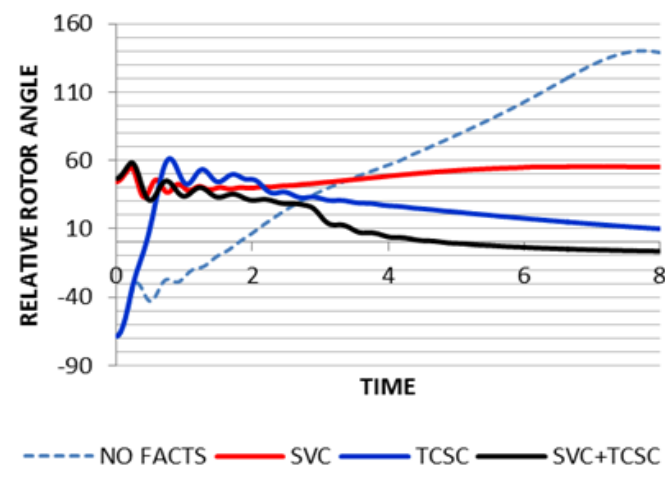

Figure 9. Relative rotor angle response to three phases fault at bus 5

The three phases fault is initiated at bus 5 at time $\mathrm{t}=0.0 \mathrm{~s}$, and the clearing time fault is $0.2 \mathrm{~s}$. Figure 9 presents the transient of power sytem.

The three phases fault happens near bus 4 on the line between bus 4 and bus 3 . The fault is initiated at time $\mathrm{t}=0.0 \mathrm{~s}$, and the clearing time fault is $0.2 \mathrm{~s}$. Following the fault clearance, line between bus 4 and bus 3 is lost. Figure 10 shows the transient of power system.

\section{Trang52}




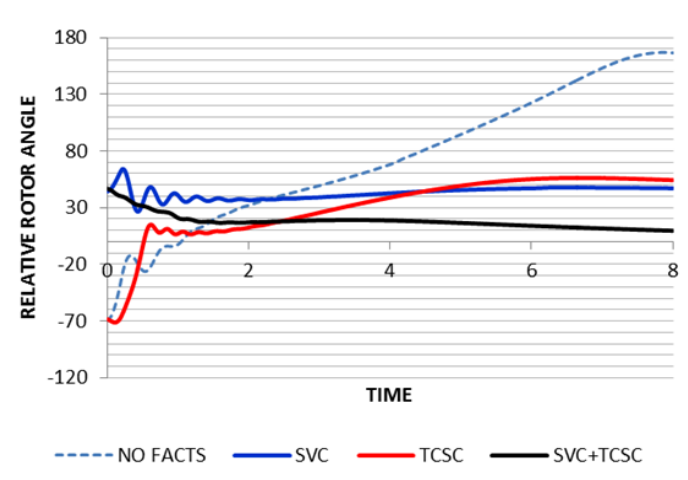

Figure 10. Relative rotor angle response to three phases fault on line between bus 4 and bus 3

From results in figures 6-7 and figures 9-10, it can be seen that, FACTS devices are capable of improving power system stability. Relative rotor angles of the power system having FACTS devices recover faster than those of the power system without FACTS devices.

\section{CONCLUSION}

In this paper, the power system stability enhancement of two-generator power system by SVC and TCSC is considered. The transient of rotor angles is compared with or without the present of FACTS devices in power system in the event of a three phases fault or switching of lines. The above simulation results of rotor angles demonstrate the effectiveness and robustness of proposed the SVC and TCSC on transient stability enhancement of power systems.

\section{Ứng dụng các thiết bị FACTS cải thiện ổn định động trong hệ thống điện}

\section{- Đặng Tuấn Khanh}

\section{- Nguyễn Văn Liêm}

Trường Đại học Bách Khoa, ĐHQG-HCM, Việt Nam

\section{TÓM TÁT}

Hệ thống điện ngày nay ngày càng phức tạp và đối diện với nhiều vấn đề về ổn định do nhu cầu sử dụng điện tăng cao. Cho nên, ổn định động đóng vai trò rất quan trọng cho việc đảm bảo chế độ vận hành của hệ thống khi có sự cố ngắn mạch hay loại trừ đường dây bị sự cố. Nội dung bài báo này tiến hành nghiên cứu mô hình của các thiết bị FACTS
(Flexible AC Transmission Systems) và ưng dụng các thiết bị FACTS để nâng cao tính ổn định của hệ thống điện. Các thiết bị FACTS có thể được dùng trong hệ thống như SVC (Static Var Compensator) bù shunt, TCSC (Thyristor-Controlled Series Capacitor) bù nối tiếp hoặc bù kết hợp cả hai shunt và nối tiếp. Mô hình toán của hệ thống điện có thiết bị 
FACTS là hệ phương trình vi phân đại số. Để giải cùng lúc hệ phương trình vi phân đại số này thì phép lập Newton-Raphson và qui tắc Trapezoidal được áp dung. Chương trình phần mềm được lập trình và mô phỏng cho các trường hợp hệ thống điện có thiết bị SVC và TCSC. Kết quả mô phỏng chứng minh các thiết bị FACTS có khả năng cải thiện và nâng cao tính ổn định của hệ thống, cu thể trong bài báo này là ổn định góc roto.

Từ khóa: Ổn định góc, FACTS, hệ thống điện, ổn định hệ thống điện, ổn định động, SVC, STATCOM, TCSC, UPFC

\section{REFERENCES}

[1]. P. Kundur. Power system stability and control. McGraw-Hill, Inc. New York, 1994.

[2]. Humpage, W.D., Bayne, J.P., and Durrani, K.E.: 'Multinode-power-system dynamic analyses', Proc. IEE, 1972, 119, (8), pp. 1167-1175.

[3]. IEEE Std 421.5-2005: 'IEEE recommended preactice for excitation system models for power system stability studies', 2005.

[4]. IEEE Working Group: 'Dynamic models for fossil fueled steam units in power system studies', IEEE Trans. Power Systems, 1991, 6 (2),pp. 753761.

[5]. Mithulananthan, N., Canizares, C.A., Reeve, J., and Rogers G.J.: 'Comparison of PSS, SVC, and STATCOM controllers for damping power system oscilations', IEEE Trans. Power System, 2003, 16, (2), pp.786-792.

[6]. Nguyen, T.T., and Gianto, R.: 'Application of optimization method for control coordination of PSSs and FACTS devices to enhance smalldisturbance stability', Proceedings of the IEEE PES 2005/2006 Transmission and Distribution Conference and Exposition, May 2006, pp. 14781485.

[7]. Del Rosso, A.D., Canizares, C.A., and Dona, V.M: 'A study of TCSC controller design for power system stability improvement', IEEE Trans. Power Systems, 2003, 18, (4), pp. 14871496.

[8]. Martins, N., Pinto, H.J.C.P, and Paserba, J.J.:'Using a TCSC for line scheduling and system oscilation damping - small signal and transient stability studies', Proc. IEEE/PES Winter Meeting, Singapoer, January 2000.
[9]. Nguyen, T.T., and Gianto, R.: 'Stability improvement of electromechaical oscilations by control coordination of PSSs and FACTS devices in multi-machine systems', Proceedings of the IEEE PES GM 2007, June 2007, pp.1-7.

[10].Nguyen, T.T., and Gianto, R.: 'Optimisationbased control coordination of PSSs and FACTS devices for optimal oscilations damping in multimachine power system', IET Gener. Transm.Distri., 2007, 1, (4), pp.564-573.

[11].CIGRE Working Group, Transmission Systems Committee: 'Modeling of static shunt var systems (SVS) for system analysis', Electra, October 1976, 51, pp. 45-74.

[12].Noroozian, M, Ghandhari, M., Anderson, G., Gronquist, J., and Hiskens, I.A.: 'A robust control strategy for shunt and series reactive compensators to damp electromechanical oscilations', IEEE Trans. Power Delivery, 2001, 16, (4), pp.812-817.

[13].CIGRE TF 31.01.08:'Modeling of power electronics equiments (FACTS) in load flow and stability program: a representation guide for power system planning and analysis', 1999.

[14].Jovcic, D., and Pilai, G.N.: 'Analytical modeling of TCSC dynamics', IEEE Trans. Power Delivery, 2005, 20, (2), pp. 1097-1104.

[15].Gianto, R.: 'Coordination of power system controllers for optimal damping of electromechanical oscillations', Energy System Centre School of Electrical, Electronic and Computer Engineering, The University of Western Australia, 2008. 